\title{
On the Recursion between Teaching and Learning
}

\author{
ZHANG GUANGLU \\ Ningbo University (China)
}

\begin{abstract}
New curriculum reform looks at the relationship between teaching and learning from new perspectives. Contrary to the traditional linear view of instruction, teaching and learning encourage ongoing recursions in the perspective of complexity theory. The recursion is embodied in different aspects: in essence, it is mutual understanding between teacher and student. As a result, it leads to the continuous transformation of the roles of teacher and student. In this sense, the relation between teacher and student becomes dynamic, while the teacher's authority becomes relative.
\end{abstract}

In the latter half of the 20th century, complexity theory as an emerging science attracted the attention of many people, and led to new understandings of nature as a complex adaptive system in a field of turbulences. This view is different from that of the modernists who assumed nature to be simple, linear and stable. Complexity refers to intertwined things (events, occurrences, ideas, etc.), with these different, interlaced and intertwined aspects forming a complex unity. The unity of complexity does not destroy the composition of its various points of diversity and difference. The famous French philosopher Edgar Morin pointed out several important principles grounding a "paradigm of complexity" (Alhadeff-Jones, 2010): (1) the importance of promoting interpretations starting from the local and the singular; (2) recognizing and integrating the irreversibility of time; (3) recognizing the impossibility to isolate single elementary units and the necessity to link the knowledge of any elements to the knowledge of the wholes they belong to; (4) the importance of organization and self-organization; (5) the principle of complex causality (including mutual causalities, feedback loops, etc.); (6) interpreting phenomena through the circular logic linking order, disorder, interactions and organization; (7) the principle of distinction, instead of disjunction, between the object, or the subject, and their environment; (8) the principle of relationship between the observer/designer and the object of study; (9) the possibility of a scientific theory of the self (e.g., through a theory of self-production and self-organization); (10) the recognition of the limits of logical demonstration with formal complex systems (e.g., Gödel, Tarski); and finally (11) thinking dialogically and through macro-concepts, as a strategy of research aiming to establish and question links and relationships between notions and concepts, and by extension between and beyond disciplines. 
Complexity theory has important implications for China's new curriculum reform, inspiring people to re-examine the relationship between teaching and learning from different aspects. Doll (2000, p.146) has pointed out: "The framework of teachinglearning can break away from the cause-effect framework that learning is the direct result of teaching and the superior-inferior relation between teaching and learning, so as to turn to another mode that teaching is attached to learning and learning plays the dominating role because of the individual's self-organization. Moreover, teaching changed its way from instruction to dialogue." Unlike the traditional linear view of teaching, the process between teaching and learning is a continuous recursion on the new perspective of complexity theory, "on the teaching level, chaos theory (complexity theory) mainly involves the concept of recursion (cycle). Through recursion, the individual can self reflect and have a sense of self and value in the self-reference experience. Currere is integrated strongly into the curriculum, and become more of a process of experience transformation, rather than requiring students to master a set of fixed knowledge" (Doll, 2000, p. 139-40).

\section{Teaching and Learning: A Recursive Concept}

Learning as a concept of recursion has a long history. In ancient Greece, Plato's theory of memory has the feature of recursion. In the Meno, Socrates points out a paradox of learning: a person cannot learn from that his knowing, because if he knows, he does not need to learn; contrawise a person cannot learn from his unknowing, because if he does not know, he will not know what to learn. In response to this paradox, Plato believed that learning is memory (recollection): it is based upon our previous experience to speculate on meaning, and all further definition or interpretation is based on the meaning of the original or amended speculation. Similarly, in John Dewey's concept of problem-solving, we can find the implication of recursion. The composition of hypothesis must be based on previous experience; with the progress of the experiment, these hypothesis may be continually revised. Plato's theory of memory and Dewey's concept of problem-solving have the feature of recursion, but they also put forward the meaning of speculation or the hypothesis needing to be constantly revised. Fundamentally speaking, in Plato's memory, recursion ends with truth; in Dewey's concept of problem-solving, recursion ends with the resolution of the problem.

Doll comments: "The purpose of accepting complexity theory is to allow a variety of perspectives in the process of 'mutual fertilization, pollination, active catalytic'. As time goes by, all kinds of network connections will be interconnected increasingly" (Doll, 2008, p. 14). The occurrence of learning is not the direct transmission from expert to novice or from teacher to students, rather the whole class explores problems / issues together in a particular situation in a recursive way. Complexity theory emphasizes selforganization and the recursion of organization, regarding teaching and learning as a continuous recursion. It includes the following recursions: between a teacher or student's prejudice and the content of text, between teachers' understanding of the text and presentation, between students' understanding of the text and a teacher's presentation, between students' mutual understanding of the text.

\section{Recursion between the text and the prejudice of teacher and students}

In the horizon of hermeneutics, the meaning of the text is not objective truth external to the teacher or students, but in the process of teachers' or students' continuous understanding and interpretation. When teachers or students understand and interpret the text, their new understanding must be based on their prejudice or previous understanding. The formation of the new understanding is the fusion of horizon between teacher or students and the text, and this is a continuous process. In this 
process, the pre-understanding or former view of the teacher or students is constantly revised.

The recursions among tradition, teacher or student and the text can be represented in Figure 1, (Gallagher, 2009, p. 86):

(d)

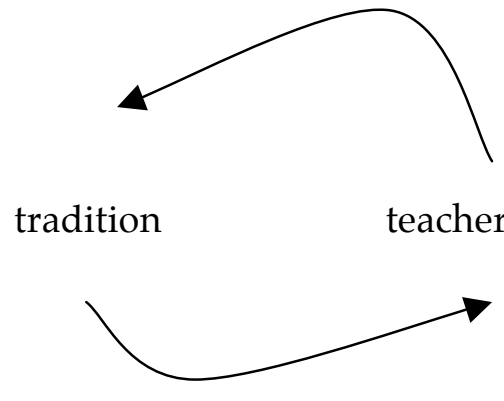

(a) (b)

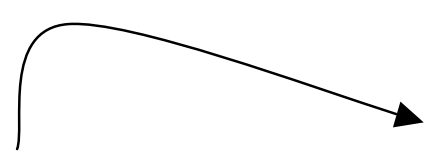

text

Figure 1. The circular relationship among tradition, teacher or student and the text

In this figure, the tradition of teacher or students plays a precedence role (a), so that it constrains the use of prejudice by the teacher or students (b), and the teacher or students employ these pre-understandings to understand and interpret the text. Response (c) will stimulate a new sense of speculation, then the relation between (b) and (c) represents the recursion between the text and the former views of the teacher and students. In the process of understanding and interpretation, the relation between teacher or students and specific tradition is also changed (d). This process is a continuous recursion.

\section{The recursion between teachers' understanding of the text and presentation}

In the view of traditional epistemology, the relation between text understanding and presentation is linear, and the teacher's understanding of the text is seen as a ultimate explanation, and it seems free from the impact of presentation. But many teachers have the following experience: after they complete the presentation, they get a better or a new understanding of the text. Ulmer (1985, p.162) claims that: "each presentation, just like reading, always adds something new to the contents of the presentation". This indicates that the understanding of text is affected by the presentation. Based on Hermeneutics, an understanding and interpretation cannot be obtained for free and for all, and ultimate understanding does not exist.

In fact, the teacher's understanding of the text plays the role of the preunderstanding for the teacher's presentation. The presentation must be in the control of the teacher's understanding of the text, but it is also affected by how to present the teacher's understanding in a good way. As a result, the teacher should constantly revise his understanding of the text according to the continuous change of the situation, especially the students' different views. So to speak, the teacher's presentation will change his understanding of the text, too. Text understanding and presentation don't form a linear process but a hermeneutics cycle. Text understanding and a teacher's presentation is internally integrated. Neither of the following two views are correct: firstly, text understanding lies in front of a teacher's understanding and teacher's understanding is the simple application of the text understanding; secondly, when the teacher understands the text, he or she can ignore the context and the preunderstanding. 


\section{The recursion between the understanding of a teacher's presentation and students' text}

The teacher presents their text understanding through the presentation, and students also have their own understanding. According to traditional epistemology, it is important that the students' text understanding is consistent with their teacher's. If it is not, the teacher would try every means to make the students reach an agreement with the teacher. However, from the perspective of philosophical hermeneutics, understanding always means different understanding, so the understanding of students and the teacher always have more or less inconsistencies. The differences are inevitable and are the premise of dialogue. Here the teacher and students gradually achieve a fusion of horizon through the dialogue. But this agreement is temporary because the teacher cannot have an absolute text understanding. Obviously, if the teacher gets it, it means the break of hermeneutics recursion between the teacher and the text. To some extent, there will be no more new learning if the understanding is consistent with another. Knowledge will always be the students' own, if the teacher successfully aids the students in their consistent understanding. The understanding of a teacher and students can achieve only a temporary consistency, as each forms a new understanding which is not absolutely objective. So, the understanding of a teacher's presentation and the students' text is a continuous recursion.

\section{The recursion of text understanding between students}

Recursion does not only happen between teacher and students, but also occurs between students. In addition to the communication between teacher and students, students also need to communicate with each other and discuss in class. Like the exchange between teacher and students, the communication between students reaches a temporary fusion through the collision of different perspectives and the circulation of different text understandings.

\section{The recursion among these recursions}

These recursions are not unrelated; on the contrary, they are linked together. For example, from the teacher's angle, the teacher's textual comprehension is shaped by the recursion of the teacher's prejudice and the content of the text; then the textual comprehension takes part in a new recursion along with the teaching process, which also plays its role in another new recursion along with the students' comprehension. From the students' angle, students' textual comprehension is shaped by the recursion of the students' prejudice and the content of the text, then the textual comprehension takes part in a new recursion along with the teacher's teaching.

\section{The Essence of Recursion: Mutual Understanding}

The essence of recursion is a "transformational interaction" (Doll, 2000, p. 194), which is the mutual understanding between teacher and students. It is "neither in the empathy of one individual for another nor in subordinating another person to our own standards; rather, it always involves rising to a higher universality that overcomes not only our own particularity but also that of the other" (Gadamer, 2004, p. 392). This means that both teacher and students are not stubborn, but open to each other, and everyone keeps open the possibility of an others' truth and each communicates with the other. That is to say, no one may have absolute understanding. As Doll (2000) says, this understanding is a continuous process of "coordinating information":

I use a common term which is 'coordinating information'--- between the teacher and the students, experience and consciousness. I think this is suitable. In my opinion, coordinating this information is the course which should be rather than presenting a 
proposition, a noun or view of the truth. During the process, everyone is actively listening to what the other says with both sympathy and critical analysis. The intention is not to confirm correct answers but to find different perspectives together through active participation with the other, thus expanding the horizon of understanding. This involvement is a change of process activities, regardless of text and reader or student or teacher. (218)

In classroom teaching, teachers should be aware that their understanding is not an absolute understanding, but needs to be perfected and amended. According to HansGeorg Gadamer, understanding is a mutual understanding, and the original form of it is consent or fusion of horizons; that is, understanding and comprehension consensus, and the purpose of text understanding is not intended to explore the author's original intention but to propose some possible truth requirements. Understanding is the result of the fusion of different horizons. Fusion of the horizon is not found but created. Each one's understanding shouldn't act as the leading or the only correct comprehension which is imposed by one party to the other; otherwise, it does not let both sides mutually carefully measure, but maybe continue to maintain the original prejudice.

\section{Recursion as a Dynamic Relation between Teacher and Students}

Based on the traditional view of linear instruction teacher and students are in binary opposition, and the teacher is always regarded as the authority just because of his or her position; however the view of recursion instruction holds that teacher's authority, and the relationship between the teacher and students is dynamic.

\section{The traditional linear view of teaching and learning : teacher's authority as identity}

Authority is a familiar word. In classroom situations, authority, power, truth, status, and prestige are linked together. A teacher's authority as identity means the authority and identity of the teacher cannot be separated. Such a kind of authority is changeless, and is only given to the teacher, and exists before the beginning of instruction. Teacher's authority as identity means that the teacher is always authoritative, correct, and privileged in classroom instruction. The roles of teacher and students are in binary opposition. Paulo Freire writes:

The teacher teaches and the students are taught; the teacher knows everything and the students know nothing; the teacher thinks and the students are thought about; the teacher talks and the students listen-meekly; the teacher disciplines and the students are disciplined; the teacher chooses and enforces his choice, and the students comply; the teacher acts and the students have the illusion of acting through the action of the teacher; the teacher chooses the program content, and the students (who were not consulted) adapt to it. (Freire, 2001, pp.25-26).

In these different roles, the teacher's role has two main functions: one is infusion, another is supervision. Teacher infuses his understanding of the material as the objective truth into students, whether through teaching or communicating. If students' responses or reactions are beyond the teacher's expectations, the teacher will play the role of supervision, and makes students walk along his preset orbit. In Michel Foucault's words, the teacher acts as the role of the supervisor. Foucault (1995) points out: "The role of surveillance is to find whether a person is qualified to his job and assesses him, punishes him. Through the supervision of individual behavior, people can make the distinction and evaluation, which is mixed with power" (p. 111). Teachers always want students to observe and follow school rules. They always expect to maintain order, rather than to promote new understanding; as a result, teaching has become a linear process. 


\section{Three different views of the teacher's authority}

\section{View of reproduction of authority}

Reproduction of the teacher's authority means that the process of instruction is just a process that reproduces authoritative opinions, values, and consciousness of the teacher. The view of reproduction holds that authority is unique to the teacher. Fundamentally speaking, reproduction denies the recursion of teaching and learning. Pierre Bourdieu and Jean-Claude Passeron (2000) have shown how teaching participate to the imposition of cultural arbitrariness by the forces of arbitrariness. Overall, mainstream cultures and power relations in a social structure are often reproduced in educational experience. In social structure, major educational system tends to ensure the monopoly of legitimate symbolic violence. In education, the reproduction of mainstream culture and power relations studied by Bourdieu and Passeron is equal to the reproduction of teacher's authority because teacher stands for the mainstream culture and value.

\section{View of digestion of authority}

Digestion of the teacher's authority means that real teaching relies on the complete digestion of teacher's authority. As long as there exists teacher's authority, there will be hegemony. Besides, the communication between teacher and students will surely be distorted, and there will not be a real consensus and liberation totally. Jurgen Habermas illustrated such a perspective. Habermas insists that authority should be changed or eliminated completely through criticism and reflection. Habermas thinks that the constraint of tradition (authority or power structure) can be canceled or at least alleviated through criticism and reflection, and the fairness of understanding relies on that of the environment. This view holds that the existence of authority is opposed to education. Only by digesting the teacher's authority fundamentally can we achieve true education. However, in this way, education itself also faces the risk of digestion.

\section{View of recognition of authority}

View of recognition of authority means that the teacher's authority is not a negative concept, and it isn't against rationality. However, the authority is based on rationality and recognition or inspection from others. Gadamer (2004, p. 361) writes: "Man's authority is not based on the action which submits or abandons rationality, but is based on some kind of recognition and approval - namely, recognizing that others are better than myself in the aspects of judgment and viewpoint. Thus his judgment is in the lead, that is, his judgment is superior to our own judgment." Associated with this, the authority is not ready for us, if we want to claim authority, we should fight and have to fight for authority. Authority relies on recognition, and thus relies on a rational action. Rationality is conscious of its limitations and recognizes that others have better ideas about this. In the view of René Descartes, the use of rationality is completely ruled out by the faith of authority. If the prestige of authority replaces our rational judgment, the contradiction between authoritative belief and rationality raised by the Enlightenment is reasonable, but this cannot rule out that authority is a possibly source of truth. In the view of Gadamer, the contradiction between authority and abstract rationality is not reasonable. Obedience to authority isn't necessarily rational: "The true foundation of authority is also an action of freedom and rationality, because the superior knows about the situation or grasps more information, that is, because the superior has a better recognition; rationality can recognize the authority of the superior fundamentally." (Gadamer, 2004, p. 361) 


\section{The view of the recursion between teaching and learning: the relativity of teacher's authority}

Doll writes: "As the chief in equals, the role of teacher has not been abandoned but to be rebuilt from outside of the students' situation to coexist with the situation. Authority is also transferred into the situation." (Doll, 2000, p. 238) The relativity of the teacher's authority means that authority comes into being gradually in the teaching process and is independent of authority and status. The status of teacher and students can be interchangeable. In the process of teaching, many scholars hold a skeptical attitude about whether we can eliminate authority completely as advocated by Habermas. For example, Foucault thought that authoritative frameworks are involved in the teaching process. Bruffee (1984) holds that "teaching authority will not appear in the dialogical education; the teacher still retains his authority, but this is not based on traditional reason" (value, truth, close to heroes or the author) (p. 650). Educational situations cannot always reach the ideal of Habermas, and it is not possible for us to eliminate authority completely in educational situations. But from another respect, authority does not mean a negative concept, and is not always the obstacle of dialogue. In fact, authority is not necessarily a threat of an equal communication relationship. We often seek for information from a well-informed man, pursuing advice from an experienced elder or searching for guidance from a friend who knows more about this field. All of these are some examples of authority. As Nicholas Burbules writes: "Reliable authority cannot be taken for granted, but to be regularly checked carefully and to be established again. In a particular moment, these authorities will play an implicit role in a continuing dialogue. The problem isn't to deny the existence of authority, but to ask what kind of authority is reasonable" (Burbules, 1993, p. 32). If we deny the influence and value of authority completely, school is no longer necessary. However, this does not mean that the teacher is always a reliable and believable authority, and will not mean that students can only learn the opinions of teacher blindly. We need to use our rationality to constantly inspect and re-establish authority. In other words, the teacher is not always the representative of authority. Authority is dynamic and comes into being in the continuing dialogue process. In fact, in some cases, students can also become the teacher's authority. Of course, this kind of recognition needs not hegemony and force but rational thinking.

From another point of view, the relativity of teacher's authority also means the digestion of teacher's authority as identity, because the identity and authority of teachers are not linked with each other. Complexity theory recognizes the view of dynamic authority. Authority is either canceled or transformed. Teaching needs the view of dynamic authority, and the teacher's role is not fixed. In the teaching process, the role of teacher and students can be transformed, so Freire puts forward the concept of teacher-student and students-teacher which means that:

The teacher is no longer just an instructor, and when communicating with students, teachers themselves can also benefit a lot. Students are taught by teachers and in turn, they also educate teachers. They grow up together through teamwork. In this process, the argument based on authority is no longer effective; In order to function, authority has to support freedom, not be against freedom. (Freire, 2001, p. 31)

The teacher does not only teach but also learns. Students do not only learn but also teach. Both teacher and students are open to each other so that both sides can obtain knowledge from instruction. So the teacher cannot claim his authority just because of teacher's identity in the system. Teachers needs to realize that real authority does not rely on a specific system, but needs the recognition of students. In the teaching process, teachers needs to listen attentively to the viewpoints of students, especially on the basis of different opinions of students; teachers should rethink their opinions and former views constantly, and realize the locality and limitation of their views. The teacher needs 
to communicate with students and form new understandings through the fusion of horizons. On the other hand, students should not accept the authoritative status of teacher blindly. Teachers' opinions need to be inspected through students' rationality. As Burbules writes:

There is no doubt that as a teacher, it means claiming legal authority to some extent. What is dangerous is that we fall into a kind of institutionalized authoritative role. In the context of dialogue relationship, the authority is not based on institutional role and privilege and untested professional assumptions. Authority should not be considered as the fixed assets or a precondition of a participant in the dialogue. (Burbules, 1993, p.34)

Authority should be considered during the continuous interaction. Thus, authority has not existed before teaching, but is gradually generated in the teaching process and exchanged between teachers and students. To quote Doll:

The organization of recursion is such a kind of organization that its consequences and outputs have formed its own cause or the necessary conditions of its production. Thus, complexity is not only an experience phenomenon (chance, randomness, disorder, intricacy, hierarchy upside and down of the internal of the phenomenon), but also a conceptual and logical problem. It makes clear that the boundaries of concepts such as 'producer' and 'product', 'cause' and 'result', 'one' and 'more' become blurred." (Doll, 2000, p. 143)

\section{References}

Alhadeff-Jones, M. (2010). Challenging the Limits of Critique in Education through Morin's Paradigm of Complexity. Studies in Philosophy and Education, 29, 5, 477-490.

Bourdieu, P. \& Passeron, J.-C. (2000). Reproduction in education, society, and culture. London: Sage.

Bruffee, K. (1984). Collaborative Learning and the "Conversation of Mankind." College English, 46.

Burbules, N. C. (1993). Dialogue in Teaching: Theory and Practice. New York and London: Teachers College, Columbia University.

Doll, W. E. (2000). A Post-Modern Perspective on Curriculum (Wang Hongyu, trans.) Beijing: Education Science Press.

Doll, W. E. (2008). Complexity and the culture of Curriculum. Educational Philosophy and Theory, 40(1), 190-212.

Foucault, M. (1995). Discipline and punish: The birth of the prison. (A. Sheridan, Trans.). New York: Vintage Books.

Freire, P. (2001). Pedagogy of the Oppressed. (Gu Jianxin, trans.) Shanghai: East China Normal University Press.

Gadamer, H. (2004). Truth and method. (Hong Handing, trans.) Shanghai: Shanghai Translation Press.

Gallagher, S. (2009). Hermeneutics and Education (Zhang Guanglu, trans.) Shanghai: East China Normal University Press.

Morin, E. (2001). Complex thinking: Conscious Science. (Chen yizhuang, trans.) Beijing: Beijing University Press.

Ulmer, G. (1985). Applied Grammatology: Post(e) Pedagogy from Jacques Derrida to Joseph Beuys. Baltimore: The Johns Hopkins University Press.

About the Author

Zhang Guanglu is Associate Professor in the College of Teacher Education at Ningbo University. He received his PhD in Curriculum Theory from East China Normal University. His research interests include curriculum theory, teacher education and literacy education. His recently published book is "Dialogical Teaching: In the Horizon of Hermeneutics" (China Social Science Press) in 2012.

(c) Copyright 2012. The author, Zhang Guanglu, assigns to the University of Alberta and other educational and non-profit institutions a non-exclusive license to use this document for personal use and in courses of instruction provided that the article is used in full and this copyright statement is reproduced. The authors also grant a non-exclusive license to the University of Alberta to publish this document in full on the World Wide Web, and for the document to be published on mirrors on the World Wide Web. Any other usage is prohibited without the express permission of the authors. 